\title{
Factors Affecting The Spiritual Well-being of Foreign Immigrant Wives in Korea
}

\author{
Hye Jin Kim ${ }^{1}$, Eun Kwang Yoo ${ }^{2}$, Eun Sil Jung ${ }^{3}$, Muyeong seak, Yang ${ }^{4}$ \\ 1 Professor, Department of nursing, Kyungbok University, Pocheon 487-717, \\ Korea \\ 2 Professor, Department of Nursing, Hanyang University, 222 Wangsimni-ro, \\ Seongdong-gu, Seoul, 133-791, Korea \\ 3 Assistant Professor, Department of nursing, Kyungbok University, Pocheon 487- \\ 717, Korea \\ 4 Professor, Department of Nursing, Jesus University, Jeonju 560-714, Korea \\ *Corresponding Author: Eun Kwang Yoo \\ 133-791, 222 Wangsimni-ro, Seongdong-gu, Seoul, Korea. \\ E-mail: jinjin051023@naver.com
}

\begin{abstract}
The purpose of this study was to identify the influencing factors that affect spiritual well-being of foreign immigrant women in Korea. Research design is descriptive survey study. The participants of this research were foreign immigrant women married to Korean men residing in the 5 cities, $S, K G(H, Y), K N(J)$ and $P$. Structured questionnaire was used to verify the degree of spiritual well-being and acculturative stress level. Data were collected from August 2010 to May 2011 and were analyzed by SPSS. As a result, the mean score of spiritual well-being was 3.31+48. Some of the variables studied prior to the research were, satisfaction of marriage life, life quality in Korea, acculturative stress level, duration of stay in Korea, degree of education and religion were the major factors that affected the spiritual well-being of the foreign immigrant wives. In order to increase the level of their spiritual well-being, the immigrant wives should be able to practice their religion of choice, and increasing the effectiveness of communication through various methods, such as Korean language education and learning the wives' languages, would also help raise the level of marriage life satisfaction. More effort to develop other intercession methods should be made.
\end{abstract}

Keywords: Immigrant Wives, Spiritual Well-being, Multiculture

\section{Introduction}

Over the past 10 years, the number of international marriages between Korean men and foreign women from countries such as China, Philippines Vietnam, Thailand and Mongolia has drastically increased [1]. In 2013, out of the total 25,963 international marriages, $71.3 \%$ was between Korean men and foreign women [2].

More than half of these foreign wives are either Chinese or Korean Chinese women, and others include Vietnamese, Japanese, Filipinas, Mongolian, Thai and Russian. Many of these marriages share the characteristics of immigration of Southeast Asian Women, and they are heavily complicated with many problems such as racial, hierarchical and gender-related issues [3]. Unlike other foreign workers in Korea, who plan to go back to their countries after working for a certain period of time, these foreign wives are married to Korean men and immigrated to stay in Korea for indefinite amount of time [4].

International marriage families often have two different cultures coexisting since husbands and wives have different cultural backgrounds. Even if both of them are Asians who have similar cultural backgrounds, they have to deal with the differences in many 
areas, such as language, daily habits, customs and religion, and dealing with all these obstacles as a family, especially with their children involved, can severely deter the formation of family unity [5]. An individual coming out of his or her own culture and joining a different culture would not only cause various group-related problems, such as ecological, societal, cultural and policy-related issues, but it would also cause many individual problems while that person is trying to become adjusted into the culture [6]. When the individual is exposed and overwhelmed with too much of the new culture in a short period of time, the individual's response to that culture can become confrontational. As a result of this maladjustment, that many foreign immigrant wives experience, the individual's spiritual well-being, along with his or her physical and mental conditions, can be severely and negatively affected.

People feel spiritual well-bing when they recognize the meaning and purpose of their lives and are satisfied with their lives in relation with God, themselves, others, society and their surroundings [7]. Spiritual well-being is a necessary component for everyone to maintain optimal physical and mental health [8], but the immigrant wives, who are away from their family and culture, find themselves feeling anxious and helpless and in need of spiritual nursing due to cultural differences and changes in their roles.

Most of the previous studies focused on spiritual well-bing of teenagers and college students, for the uncertainty and sudden changes of their lives, and other socially disadvantaged group of people, such as elders, physically challenged and women who go through menopause; however, there hasn't been any studies focusing on spiritual wellbing of foreign immigrant women. Dealing with the foreign immigrant wives' already existing physical and mental pain is important, but nursing them spiritually would significantly help decrease their emotional burdens as well; therefore, this study investigated the foreign immigrant wives' level of spiritual well-bing in order to identify the influencing factors, in hopes of helping solve some of their problems in the future.

\section{Method}

\subsection{Research Design}

This was a descriptive research designed to find out the factors that can affect the spiritual well-being of the foreign immigrant wives of multicultural family in Korea. It was designed to provide basic data for developing spiritual well-being nursing intervention program.

\subsection{Participants Research Procedure and Data Collection}

The participants of this research were foreign immigrant women married to Korean man residing in the 5 cities, $\mathrm{S}, \mathrm{KG}(\mathrm{H}, \mathrm{Y}), \mathrm{KN}(\mathrm{J})$ and $\mathrm{P}$. They all agreed to participate in this study by reading the documents given to them in their own native language. 448 participants' responses were used out of 731 after eliminating some participants' insufficient responses.

\subsection{Tools and Materials}

The main tool used for this study was the survey designed to grasp the general characteristics of the immigrant women, their immigration, their married life and their acculturative stress and spiritual well-being. The contents of the characteristics included the immigrant women's age, age of their husbands, their native country, duration of stay in Korea, level of education, family's monthly income, employment status, their Korean skill level, their husbands' language skill of the wife's country, marital satisfaction and their overall life quality in Korea. In order to measure the level of acculturative stress, Accumulation Stress Scale, originally developed by Cervantes to measure the stress level 
of Spanish people when they were going through culture related stress[9] and translated and modified into English by Alderete[10] to measure the degree of stress of Mexican immigrant workers, was used. This scale consists of three subordinate sections and total 13 questions: 4 questions dealing with discrimination experiences, 3 questions dealing with language barrier and 6 questions regarding legal status. For the responses, the Likert scale was used: 1 being "Not at all" to 5 being "Almost always", and higher scores indicated higher levels of stress. For reliability, Cronbach's alpha was .893. The level of spiritual well-being was measured by JAREL Spiritual Well-Being Scale, developed by Hungelmann[11]. The JAREL Spiritual Well-being Scale was developed as an assessment tool to provide a way of establishing a nursing diagnosis of spirituality. The spiritual wellbeing was measured with 20 questions, also using the Likert scale, and higher scores indicated higher levels of spiritual well-bing. For reliability, Cronbach's alpha was .842 .

\subsection{Data Collection Method and Ethical Consideration}

This study was reviewed by Institutional Review Board (No. 2009-09), and data were collected from August, 2010 to May, 2011. The researchers and the research assistant visited the multicultural center, immigrant women's centers and public health centers and explained the purpose, intention and anonymity of this study, and then the questionnaire was given to the immigrant women upon their agreement.

\subsection{Data Analysis}

All the collected data were computerized with SPSS Win 20.0. Characteristics of the foreign immigrant wives were indicated by frequency and percentage, and the need for health education by different characteristics was analyzed by t-test and ANOVA and Scheffe's test.

\section{Results}

\subsection{General Characteristics of Participants}

The participants' average age was $29.53 \pm 6.48$, the average age of entering Korea was $25.50 \pm 5.56$, their husbands' average age was $41.34 \pm 6.38$ and the average age difference with their husbands' age was $11.80 \pm 7.57$. $56.5 \%$ of the participants were Vietnamese and $35.3 \%$ were Chinese. $28.2 \%$ of the participants lived less than 2 years in Korea, $34.4 \%$ lived longer than 2 years and less than 4 years, and $37.4 \%$ lived longer than 4 years. $83.8 \%$ came to Korea because of their marriage, 34 people $(7.7 \%)$ for employment. For the questions regarding their housemate, where one than one choice of answer was possible, if applicable, $84.6 \%$ of the participants responded that they lived with their husbands, $30.6 \%$ lived with their parents-in-law, and $2.7 \%$ or 12 of them lived with their own parents. $42.0 \%$ of the participants were high school graduates, their husband were $59.3 \%$. $51.6 \%$ of participants and $45.8 \%$ of their husbands had religion. $70.3 \%$ of couple has same religion. The average income for the family was $2,317,800$ won and $38.5 \%$ of the participants had job. $89.1 \%$ of them communicated with their husbands in Korean, $3.4 \%$ used English, 3.9\% used the wives' language, and 3.6\% rarely spoke to each other (Table1). 
Table 1. General Characteristics

$(\mathrm{N}=448)$

\begin{tabular}{|c|c|c|c|}
\hline Characteristics & Categories & $n(\%)$ & $\mathrm{M} \pm \mathrm{SD}$ \\
\hline \multirow[t]{3}{*}{ Age(year) } & $19 \sim 29$ & $256(57.1)$ & $29.53 \pm 6.48$ \\
\hline & $30 \sim 39$ & $161(35.9)$ & \\
\hline & $\geq 40$ & $31(6.9)$ & \\
\hline \multirow[t]{5}{*}{ Age of entrance(year) } & $18 \sim 20$ & $52(11.6)$ & $25.50 \pm 5.56$ \\
\hline & $21 \sim 25$ & $221(49.3)$ & \\
\hline & $26 \sim 30$ & $112(25.0)$ & \\
\hline & $31 \sim 40$ & $51(11.4)$ & \\
\hline & $\geq 40$ & $12(2.7)$ & \\
\hline \multirow{3}{*}{$\begin{array}{l}\text { Age of husband(year) } \\
\qquad n=448\end{array}$} & 24 39 & $158(36.2)$ & $41.34 \pm 6.38$ \\
\hline & $40 \sim 49$ & $240(53.6)$ & \\
\hline & $\geq 50$ & $39(8.7)$ & \\
\hline \multirow[t]{4}{*}{ Couple's age gap(year) } & $-13 \sim 0$ & $31(7.1)$ & $11.80 \pm 7.57$ \\
\hline & $1 \sim 10$ & $153(35.0)$ & \\
\hline & $11 \sim 20$ & $207(47.4)$ & \\
\hline & $\geq 21$ & $46(10.5)$ & \\
\hline \multirow[t]{3}{*}{ Native country } & China & $158(35.3)$ & \\
\hline & Vietnam & $253(56.5)$ & \\
\hline & others & $37(8.3)$ & \\
\hline \multirow{3}{*}{$\begin{array}{l}\text { Length of residence in } \\
\text { Korea(year) }\end{array}$} & $<2$ & $120(28.2)$ & $49.60 \pm 40.52$ \\
\hline & $2 \sim 4$ & $146(34.4)$ & (month) \\
\hline & $\geq 4$ & $159(37.4)$ & \\
\hline \multirow[t]{3}{*}{ Reason for coming to Korea } & Marriage & $372(83.8)$ & \\
\hline & Employment & $34(7.7)$ & \\
\hline & Others & $38(8.6)$ & \\
\hline \multirow{5}{*}{$\begin{array}{c}\text { Housemate } \\
\text { (More than one response } \\
\text { possible, if applicable) }\end{array}$} & alone & $29(6.5)$ & \\
\hline & husband & $379(84.6)$ & \\
\hline & Children & $263(58.7)$ & \\
\hline & Husband' parents & $137(30.6)$ & \\
\hline & Her parents & $12(2.7)$ & \\
\hline \multirow[t]{4}{*}{ Education } & Less Middle school & $176(39.7)$ & \\
\hline & High school & $186(42.0)$ & \\
\hline & College & $68(15.3)$ & \\
\hline & Others & $13(2.9)$ & \\
\hline \multirow[t]{4}{*}{ Education of husband } & Less Middle school & $72(16.6)$ & \\
\hline & High school & $258(59.3)$ & \\
\hline & College & $92(21.1)$ & \\
\hline & Others & $13(3.0)$ & \\
\hline
\end{tabular}


Table 1. General Characteristics (Continuing)

$(\mathrm{N}=448)$

\begin{tabular}{|c|c|c|c|}
\hline Characteristics & Categories & $n(\%)$ & $M \pm S D$ \\
\hline \multirow[t]{2}{*}{ Religion } & None & $217(48.4)$ & \\
\hline & Have & $231(51.6)$ & \\
\hline \multirow[t]{2}{*}{ Religion of husband } & None & $243(54.2)$ & \\
\hline & Have & $205(45.8)$ & \\
\hline \multirow[t]{2}{*}{ Same Religion of couple } & No & $133(29.7)$ & \\
\hline & Yes & $315(70.3)$ & \\
\hline \multirow{3}{*}{$\begin{array}{l}\text { Family's monthly income } \\
\qquad(\mathrm{n}=225)\end{array}$} & 200 or less & $124(55.1)$ & $231.78 \pm 108.03$ \\
\hline & $201 \sim 300$ & $73(32.4)$ & (Unit: 10,000won) \\
\hline & Over 301 & $28(12.4)$ & \\
\hline \multirow{2}{*}{$\begin{array}{c}\text { Job } \\
(n=400)\end{array}$} & Yes & $154(38.5)$ & \\
\hline & No & $246(61.5)$ & \\
\hline \multirow[t]{4}{*}{ Language* $^{*}$} & Korean & $366(89.1)$ & \\
\hline & English & $14(3.4)$ & \\
\hline & Native language & $16(3.9)$ & \\
\hline & Almost no dialogue & $15(3.6)$ & \\
\hline
\end{tabular}

*Language: The primary language used to communicate with each other

\subsection{Levels of Acculturative stress, Spiritual well-being and related Variables}

The immigrant women's ability to speak Korean language was 2.43 . On the other hand, the ability of their husbands to speak their wives' language was 1.79 , indicating that their skills were poorer. The degree of married life satisfaction was 3.52, indicating they were happier than average, and the life satisfaction level in Korea was 3.44. The Participants' average acculturative stress was 2.43 , which indicated that the stress level was lower than

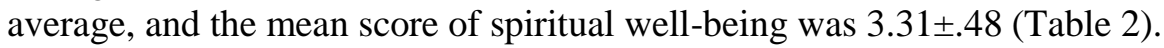

Table 2. Levels of Acculturative Stress, Spiritual Well-being and Related Variables

\begin{tabular}{cccccc}
\hline Variables & $\mathbf{n}$ & Min. & Max. & M \pm SD \\
\hline Korean language ability of immigrant women & 408 & 1 & 4.54 & 2.43 .70 \\
Ability of husband in language of the wife's & 434 & 1 & 5 & 1.79 & 1.13 \\
country & 448 & 1 & 5 & 3.52 .88 \\
Married life satisfaction & 373 & 1 & 5 & 3.44 .70 \\
Satisfaction with life in Korea & 408 & 1 & 4.54 & 2.43 .70 \\
Acculturative stress & 448 & 1 & 4.80 & 3.31 .48 \\
Spiritual well-being & & & & \\
\hline
\end{tabular}




\subsection{Differences of Acculturative Stress, Spiritual Well-being according to characteristics}

According to the participants' sociological characteristics, the factors that made significant differences in acculturative stress were the participants' age ( $\mathrm{F}=9.681$, $\mathrm{p}=.000)$, couple's age gap $(\mathrm{F}=8.003, \mathrm{p}=.000)$, native country $(\mathrm{F}=4.102, \mathrm{p}=.017)$, duration of stay in Korea $(\mathrm{F}=11.492, \mathrm{p}=.000)$, education $(\mathrm{F}=6.081, \mathrm{p}=.000)$, same religion of couple $(\mathrm{F}=-2.372, \mathrm{p}=.018)$, family's monthly income $(\mathrm{F}=8.991, \mathrm{p}=.000)$, Job $(\mathrm{F}=-2.968$, $\mathrm{p}=.003)$, and the primary language used to communicate with each other $(\mathrm{F}=6.200$, $\mathrm{p}=.000)$.

The factors that made significant differences in spiritual well-being were the participants' age $(\mathrm{F}=4.521, \mathrm{p}=.011)$, native country $(\mathrm{F}=32.977, \mathrm{p}=.000)$, duration of stay in Korea $(\mathrm{F}=6.610, \mathrm{p}=.001)$, education $(\mathrm{F}=6.864, \mathrm{p}=.000)$, religion $(\mathrm{F}=8.242, \mathrm{p}=.000)$, religion of husband $(\mathrm{F}=4.600, \mathrm{p}=.000)$, and the primary language used to communicate with each other $(\mathrm{F}=4.574, \mathrm{p}=.004)$. (Table 3$)$.

Table 3. Differences of Acculturative Stress, Spiritual Well-being According to Characteristics

$(\mathrm{N}=448)$

\begin{tabular}{cccccccc}
\hline Characteristics & Categories & \multicolumn{3}{c}{ Acculturative stress } & \multicolumn{3}{c}{ Spiritual well-being } \\
\hline Age(year) & $19 \sim 29$ & 2.56 & .63 & $9.681(.000)$ & 3.25 & .46 & $4.521(.011)$ \\
& $30 \sim 39$ & 2.25 & .76 & Post-Hoc: $\mathrm{a}>\mathrm{b}$ & 3.40 & .49 & Post-Hoc: $\mathrm{a}<\mathrm{b}$ \\
& $\geq 40$ & 2.29 & .68 & & 3.31 & .60 & \\
Couple's age & $-13 \sim 0$ & 2.05 & .73 & $8.003(.000)$ & 3.47 & .43 & $2.224(.085)$ \\
gap(year) & $1 \sim 10$ & 2.36 & .73 & Post-Hoc: & 3.33 & .53 & \\
& $11 \sim 20$ & 2.45 & .65 & a<c<d & 3.28 & .47 & \\
& $\geq 21$ & 2.82 & .60 & & 3.21 & .37 & \\
Native country & China & 2.30 & .74 & $4.102(.017)$ & 3.31 & .48 & $32.977(.000)$ \\
& Vietnam & 2.51 & .65 & Post-Hoc: $\mathrm{a}<\mathrm{b}$ & 3.22 & .41 & Post-Hoc: $\mathrm{a}<\mathrm{c}$ \\
& others & 2.43 & .76 & & 3.88 & .58 & $\mathrm{~b}<\mathrm{c}$ \\
Length of & $<2$ & 2.65 & .65 & $11.492(.000)$ & 3.22 & .51 & $6.610(.001)$ \\
residence in & $2 \sim 4$ & 2.45 & .64 & Post-Hoc: $\mathrm{a}>\mathrm{c}$ & 3.26 & .43 & Post-Hoc: $\mathrm{a}<\mathrm{c}$ \\
Korea(year) & $\geq 4$ & 2.24 & .73 & b>c & 3.41 & .49 & $\mathrm{~b}<\mathrm{c}$ \\
\hline
\end{tabular}

Table 3. Differences of Acculturative Stress, Spiritual Well-being According to Characteristics (Continuing)

$(\mathrm{N}=448)$

\section{Characteristics Categories Acculturative stress Spiritual well-being}

\begin{tabular}{|c|c|c|c|c|c|c|c|}
\hline \multirow[t]{4}{*}{ Education } & $\begin{array}{l}\text { Less Middle } \\
\text { school }\end{array}$ & 2.51 & .68 & $6.081(.000)$ & 3.20 & .39 & $6.864(.000)$ \\
\hline & High school & 2.47 & .68 & Post-Hoc: $a>b$ & 3.34 & .50 & Post-Hoc: $a<b$ \\
\hline & College & 2.14 & .70 & $b>c$ & 3.46 & .56 & $a<c$ \\
\hline & Others & 2.03 & .74 & & 3.54 & .67 & \\
\hline Religion & None & 2.44 & .66 & $-.267(.789)$ & 3.12 & .40 & $8.242(.000)$ \\
\hline
\end{tabular}




\begin{tabular}{|c|c|c|c|c|c|c|c|}
\hline \multirow{3}{*}{$\begin{array}{l}\text { Religion of } \\
\text { husband }\end{array}$} & Have & 2.42 & .73 & & 3.48 & .49 & \\
\hline & None & 2.48 & .67 & $-1.655(.099)$ & 3.21 & .43 & $4.600(.000)$ \\
\hline & Have & 2.36 & .73 & & 3.42 & .52 & \\
\hline \multirow{2}{*}{$\begin{array}{l}\text { Same Religion of } \\
\text { couple }\end{array}$} & No & 2.55 & .61 & $-2.372(.018)$ & 3.33 & .54 & $-.520(.604)$ \\
\hline & Yes & 2.38 & .73 & & 3.30 & .46 & \\
\hline \multirow{3}{*}{$\begin{array}{c}\text { Family's monthly } \\
\text { income } \\
n=225\end{array}$} & 200 or less & 2.40 & .67 & $8.991(.000)$ & 3.26 & .49 & $2.266(.106)$ \\
\hline & $201 \sim 300$ & 2.35 & .76 & Post-Hoc: & 3.32 & .59 & \\
\hline & Over 301 & 1.74 & .67 & $a>b>c$ & 3.49 & .51 & \\
\hline \multirow{2}{*}{$\begin{array}{c}\text { Job } \\
n=400\end{array}$} & Yes & 2.29 & .73 & $-2.968(.003)$ & 3.35 & .53 & $1.272(.204)$ \\
\hline & No & 2.51 & .66 & & 3.28 & .46 & \\
\hline \multirow[t]{4}{*}{ Language* $^{*}$} & Korean & 2.38 & .69 & $6.200(.000)$ & 3.32 & .48 & $4.574(.004)$ \\
\hline & English & 2.17 & .75 & Post-Hoc: & 3.72 & .54 & Post-Hoc:b>a \\
\hline & $\begin{array}{c}\text { Native } \\
\text { language }\end{array}$ & 2.71 & .54 & $a<d, b<d$ & 3.12 & .52 & $b>c, b>d$ \\
\hline & $\begin{array}{l}\text { Almost no } \\
\text { dialogue }\end{array}$ & 3.10 & .63 & & 3.17 & .28 & \\
\hline
\end{tabular}

*Language: the primary language used to communicate with each other

\subsection{Correlations of Related Variables with Spiritual Well-being}

The variables were Korean language ability of immigrant women, husbands' fluency in their wives' language, married life satisfaction, satisfaction of life in Korea, acculturative stress and the spiritual well-being. After analyzing the correlations of all these variables, the higher level of the husbands' fluency in the wives' native language indicated higher level of the immigrant wives' spiritual well-being. Also, the higher the satisfaction level of their marriage life and life in Korea, the higher the level of spiritual well-being.

Table 4. Levels of Acculturative Stress, Spiritual Well-being and Related Variables

\begin{tabular}{ccc}
\hline Variables & \multicolumn{2}{c}{ Spiritual well-being } \\
\cline { 2 - 3 } & $\mathbf{r}$ & $\mathbf{p}$ \\
\hline Korean language ability of immigrant women & .004 & .932 \\
Ability of husband in language of the wife's & .180 & .000 \\
country & .159 & .001 \\
Married life satisfaction & .147 & .005 \\
Satisfaction with life in Korea & -.148 & .003 \\
Acculturative stress & & \\
\hline
\end{tabular}

\section{Discussion}

Not only does modern society put a lot of interest in maintaining both physical and psychological health, but it also attempts to improve people's spiritual health. There has been a lot of effort to help maintain and manage the health of socially disadvantaged groups of people, such as women, elders and teenagers. The foreign wives who immigrated to Korea through international marriages around the year 2000 would most likely suffer from various problems, such as unfamiliar environment, unstable income, lack of family members that are supportive and maladjustment to Korean culture, which will eventually lead to other problems associated with their spiritual well-being. This 
study was designed to investigate the foreign immigrant wives' level of spiritual wellbing in order to identify the influencing factors. It would, in turn, provide fundamental data to establish public health policy that can be applied to the field of nursing, which would greatly help the immigrant women in the future. The average value of foreign immigrant women's acculturative stress came out $2.43 \pm .70$, which was pretty low. The immigrant women who settled in Daegu area had the acculturative stress level of 2.76 [12], while another study indicated that Korean women who settled in the United Kingdom had the stress level of 2.49 [13]. The fact that couples with larger age gap and the immigrant women who didn't stay in Korea for long had higher level of stress matched the result of previous studies $[12,13]$. Although the study didn't focus heavily on whether the participants had religion or not, the immigrant women who had the same religion as their husbands had lower level of acculturative stress. Also, the immigrant women who rarely talk to their husbands had higher level of stress compared to the couples who do talk more frequently, regardless of the effectiveness of their communication. Maintaining strong relationship with their husbands and the ability to relate to each other were the key factors that reduced the stress level.

The foreign immigrant wives' perceived spiritual well-being came out 3.31 \pm .48 , while another study, although different tools were used, that focused on the relationship between spiritual well-being and depression of women who go through menopause had the perceived spiritual well-bing of 2.90 out of 4 [14] and that of elderly women who live by themselves was 3.77 out of 6 [15]. This indicated that the spiritual well-being of the foreign immigrant wives came out lower than that of women who go through menopause but higher than that of elderly women who live by themselves. The perceived spiritual well-being of Filipina, Cambodian and Mongolian women came out higher than that of Chinese and Vietnamese women, and this is thought to be caused by the differences of their life quality back home and their anticipations of life in Korea. The foreign wives with longer duration of stay in Korea and the wives whose husbands have religion had higher level of perceived spiritual well-being. This matched the results of previous studies that indicated religion plays a significant role in raising the spiritual well-being of elderly women who live by themselves, stay-home elders and hospitalized patients [14-16].

The foreign immigrant wives' Korean skills or their husbands' increased skills in the wives' languages were some of the major factors that significantly reduced the level of stress and increased the spiritual well-being. Also, the level of satisfaction of life in Korea and the marriage life in general also played significant role in increasing the spiritual well-being as well. Many of these factors also influence other socially disadvantaged groups of people and their spiritual well-being, but more detailed and generalized studies need to be conducted in the future.

\section{Conclusion}

This was a descriptive study designed to identify the influencing factors that affect spiritual well-being of foreign immigrant women in Korea. According to this study, satisfaction of marriage life, life quality in Korea, acculturative stress level, duration of stay in Korea, degree of education and religion were the major factors that affected the spiritual well-being of the foreign immigrant wives. In order to increase the level of their spiritual well-being, the immigrant wives should be able to practice their religion of choice, and increasing the effectiveness of communication through various methods, such as Korean language education and learning the wives' languages, would also help raise the level of marriage life satisfaction. More effort to develop other intercession methods should be made. Also, more detailed guidelines for nursing professionals should be developed in order to take care of the foreign immigrant wives' spiritual well-being, as well as their physical and mental health. 


\section{Acknowledgements}

This study was funded by the Korea Research Foundation (E32100900000000852).

\section{References}

[1] E. S. Jung, E. K. Yoo and H. J. Kim, "Lived experience of immigrant women through marriage immigrant women in everyday life in South Korea", Asia Life Sciences Supplement, no.10, (2014), pp. 127-138

[2] H. J. Kim, E. K. Yoo, E. S. Jung and Y. M. Kim, "A strong Needs for Health education and it's influencing factors for Foreign women of Multi- cultural family in Korea", Information, no. 17(10B), (2014), pp.5347-5352.

[3] M. S. Jang and O. K. Lee, "A research on the economic independence of marriage immigrant women in Seoul through the capacity development for employment or businesses", Seoul foundation of women \& family, (2009).

[4] H. J. Kim, "A Study of Spousal Support, the Demand for Health Education, and Quality of Life for Married Female Immigrants", Korean Journal of Women Health Nursing, vol. 1, no. 14, (2008), pp. 511.

[5] H. J. An, "Study on Marriage Satisfaction of Couple of International Marriage -Focused on Couples of Korean Men and Philippine Women", Unpublished doctor's thesis, Chodang University, (2003).

[6] M. A. Gibson, "Immigrant adaptation and patterns of acculturation", Human Development, no. 44, (2001), pp. 43-54.

[7] R. F. Paloutzian and C. W. Ellison, "Loneliness, spiritual well-being and the quality of life", L. A. Peplau \& D. Perlman (Ed.), Loneliness; A sourcebook of current theory, research, and therapy, John Wiley \& Sons, (1982), pp. 224-237..

[8] K. D. Phillips, K. S. Mock, C. M. Bopp, W. A Dudgeon and G. A. Hand, "Spiritual well-being, sleep disturbance, and mental and physical health status in HIV-infected individuals", Issues in Mental Health Nursing, no.27, (2006), pp.125-139.

[9] R. C. Cervantes, A. M. Padilla and S. N. de Salgado, "The Hispanic stress inventory: A culturally relevant approach to psychosocial assessment", Psychosocial Assessment: A Journal of Consulting and Clinical Psychology, no. 3, (1991), pp. 438-447.

[10] E. Alderete, W. Vega, B. Kolody and S. A. Gaxiola, "Depressive symptomatology: Prevalence and psychosocial risk factors among Mexican migrant farmworkers in California", Journal of Community Psychology, no. 27, (1999), pp. 457-471.

[11] J. Hungelmann, E. K. Rossi, L. Klassen and R. Stollenwerk, "Development of the JAREL spiritual wellbeing scale", Classification of nursing diagnoses: proceedings of the eight conference held in St. Louis, MO, March, (1988), pp. 393-398.

[12] H. S. Kim, "Impacts of Acculturation \& Acculturative Stress on Depression among International Marriage Migrant Women", Health and Social Science, no. 32, (2012), pp. 39-70.

[13] H. W. Park, "Acculturative Stress and Mental Health of Korean Women Living in UK", Korea Contents Association Review, vol. 8, no. 10, (2010), pp. 308-316.

[14] J. E. Heo and Y. S. Tae, "Influence of Spiritual Wellbeing and Social Support on Depression in Middleaged Women", Korean Journal of Adult nursing, vol. 2, no. 26, (2014), pp.181-190.

[15] K. J. Lee and E. Lee, "Factors Affecting Spiritual Well-being in Underprivileged Older Women Living Alone", Journal of Korean Academy Fundam Nursing, , vol. 14, no. 18, (2011), pp. 538-546.

[16] H. J. Kim, E. K. Yoo, E. S. Jung and M. S. Yang, "Spiritual Well-being of Foreign Immigrant Women Married to Korean”, Advanced Science and Technology Letters, no. 61, (2015), pp.81-84.

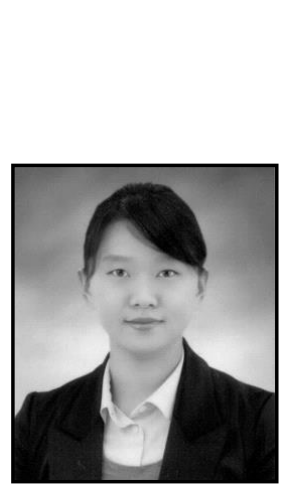

Authors

Hye Jin Kim, RN, Ph.D, she teaches Nursing at the School of Nursing, Kyungbok University located in Gyeonggi. She began her career as a faculty of Women's Health Nursing in 2001 after receiving B.A. (1997) from Hanyang University, M.S. (2005)and a Ph.D.(2008) in Nursing from Hanyang University. She is coauthor 'My mom health JUMP - Joy Ultra Mom Program' \& 'My mom health Sanhujori'. She participated in the study 'Development of program for the married immigrant women and family' \& 'Development of WISE HF Sanhujori Guideline'. The 


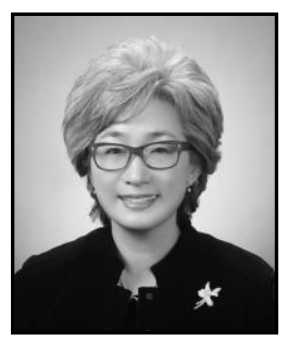

main research interests include multicultural women's health and childbirth and Sanhujori, contraception.

Eun Kwang Yoo, RN, Ph.D, she teaches Nursing at the School of Nursing, Hanyang University located in Seoul Korea. She began her career as a faculty of Women's Health Nursing in 1982 after receiving B.A. (1978) from Hanyang University, M.S.(1980) in Nursing from Yonsei University, and a Ph.D. in Nursing (1993) from University of California, San Francisco(UCSF) as a Fulbright Doctoral Grantee. She has been a Fulbright Visiting Scholar at Boston College, School of Nursing (2007 2008), a vice president of Korean Fulbright Alumni since 2004 and a Chair of Korean Sanhujori Academy since 1999. Professor Yoo, a leading authority on Women's health nursing, especially the pioneer of Sanhujori, Korean traditional postpartum care, and IPC (Integrated Postpartum Care), is the author of 'East meets West- Integrated postpartum care - Sanhujori \& nursing care' and 'Contemporary Sanhujori' and co-author of 24 books including 'My mom health JUMP Joy Ultra Mom Program' \& 'My mom health Sanhujori' with many other articles. Her recent research interest is to develop a system for connection of health knowledge with consumer's everyday life. She was selected as a Marquis Who's Who in America (2013 Edition) and TOP 100 Health Professionals in America 2013.

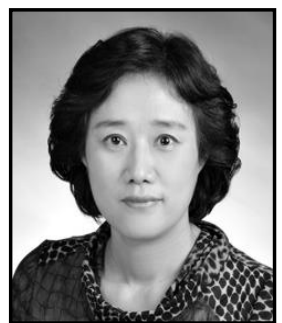

Eun Sil Jung, RN, Ph.D., she teaches Nursing at the School of Nursing, Kyungbok University located in Gyeonggi province of South Korea, since 2004. She began her career as a faculty of Women' s Health Nursing in 2004 after receiving M.S.(2002) in Nursing from Hanyang University, and a Ph.D. in Nursing (2006) at the same university. She is also a member of Korean Sanhujori Academy, and she focuses her studies on elders and multicultural women's health.

Muyeong seak, Yang, RN, Ph.D, she teaches Nursing at the School of Nursing, Jesus University located in JeonJu Korea. She began her career as a head nurse of InJe's medical university hospital in 1984 2012, after receiving B.A. (1993) from Catholic University, in Nursing from Hanyang University, and a Ph.D. in Nursing (2007) at the same university. She is also a member of Korean Sanhujori Academy, and she focuses her studies on women's health. Author's profile. 